\title{
Strengthening Quality Research Ethics Review in a Developing Country
}

\author{
Hsu Mon Aung ${ }^{1}$, Khin Thet Wai ${ }^{2}$, Yin Thet Un $\mathrm{Oo}^{3}$, Hlaing Myat $\mathrm{Thu}^{4}$, \\ Zaw Than Htun ${ }^{5}$, Henry Silverman ${ }^{6}$ \\ ${ }^{1}$ Research Officer, \\ ${ }^{2}$ Chairperson, Institutional Review Board, \\ ${ }^{3}$ Deputy Director, \\ ${ }^{4}$ Deputy Director General, \\ ${ }^{5}$ Director General \\ ${ }_{1,2,3,4,5}$ Department of Medical Research, No. 5 Ziwaka Road, 11191 Dagon Township, Yangon, \\ Myanmar. \\ ${ }^{6}$ University of Maryland, USA \\ Corresponding Author: Khin Thet Wai \\ E-mail: khinthetwaidmr@gmail.com
}

\begin{abstract}
Background: The high volume of research proposals increases the workload of Institutional Review Boards (IRBs). Above all, ethical oversight ensures the quality improvement of research. On the other hand, thorough scrutiny of minimal risk proposals including the decisions to waive for informed consent may enhance rapid review cycles. The objective of the study was to determine the nature of ethical review process and assess the opinions of IRB members regarding strengthening the quality of ethics review.

Methodology: Using existing IRB records, we analyzed the categories of registered research proposals at the IRB, Department of Medical (DMR), Myanmar ( $n=703)$ between January 2016 and December 2019. We assessed the opinions of current IRB members $(n=9)$ of DMR by a selfadministered semi-structured questionnaire containing five items on a scale from one to 10 alongside narrative comments.

Results: Across the study period, operational research, program evaluation, and community interventions predominated (56\%) over biomedical research. In 2019, the proportion of expedited reviews and the frequency of hearing-sessions were higher than the remaining years. Three case studies supported the empirical evidence of relevant decisions for major modifications, minor modifications, and exemption. Furthermore, the IRB members preferred sustained efforts in: capacity building, modification of standard operating procedures, and especially networking (modal rating of 9 ).

Conclusions: This study elucidates the satisfactory progress and achievements in ethical review despite a few challenges. Continuing evaluation of institutional capacity for research ethics might underscore discrepancies that would allow for improvement in quality ethics review. Future research on the development of a framework for feasible and efficient accreditation mechanism with stronger administrative support is critical.
\end{abstract}

Keywords: quality, research, review, ethics. 


\section{Introduction}

Protecting human research participants is the inherent and vital function of the Institutional Review Boards (IRBs) either in the context of developing or the developed countries [1]. However, the high volume of research proposals increases the workload thereby affecting the timely and quality reviews of IRBs especially in resource-constrained settings [2]. In this connection, sustained ethical oversight and accreditation mechanisms could ensure the quality improvement of research [3]. On the other hand, thorough scrutiny of minimal risk proposals including the decisions to waive for informed consent may enhance rapid review cycles [4-7].

There has been a restructuring process of the ethics review committee (ERC) at the Department of Medical Research (DMR) in terms of its functions following the recognition by the "Strategic Initiative for Developing Capacity in Ethical Review and Forum for Ethical Review Committees in Asia and the Western Pacific" (SIDCER-FERCAP) at the General Assembly in November 2018. The comprehensive steps for accreditation started with the team of independent assessors who thoroughly examined the local ethical guidelines, laws, and regulations, membership of the research ethics committee (REC) and documentation of expertise of both members and the secretarial staff. Also, the extensive review covered the standard operating procedures (SOP), random checks of the submitted research proposals within past three years, evaluation of documentation and archiving at the office of the REC, evaluation of the training curriculum and training records, review of the follow-up policy and procedures after the ethics review process, and examining the agenda and minutes of board meetings. Moreover, the independent evaluators observed and rated the real-time conduct of the board meeting and eventually followed by interviews with REC Chair, members and secretarial staff to clarify about appointment, roles, procedures and suggestions to improve quality reviews. Since its recognition by the SIDCERFERCAP, there were updates in its SOP inclusive of the submission checklist, the reviewer assessment form, the template for letter of communication to Principal Investigators and in organizing the review meetings [Annual Report to FERCAP, 2019].

In 2019, the Ministry of Health and Sports, Myanmar has reformed and reorganized the structure of ERC (DMR) as the 'Institutional Review Board' (IRB) with 15 members (at least 8 members including one non-affiliated community member to fulfil the quorum) and rejuvenated with young members to work cohesively with senior and experienced members. In the recently reformed IRB (DMR), seven experienced members and three secretariat members of the former ERC (DMR) remained as a Chair and member status together with five new members who have diverse expertise in biomedical, clinical, public health, epidemiology, and social science. A new secretariat team formed in 2019 comprised three permanent members and three rotating researchers every three months. The current version of the revised SOPs and the related sample forms at IRB (DMR) has applied ethical principles stated in the Belmont Report and Helsinki Declaration, complies with existing laws, regulations as well as the National Health Research Policy (2017) and the National Health Plan (2017-2021) in Myanmar, and also followed the good clinical practice guidelines published by the International Conference on Harmonisation of Good Clinical Practice (ICH-GCP) [8]. Among others, the updated manual for SOPs after accreditation mainly covers the following:

1. Qualification of IRB members through the experience and expertise;

2. The detail description of IRB review policy and procedures to inform IRB members and secretarial staff and researchers and related organizations;

3. A comprehensive description of the IRB rules for submission, review, communication, resubmission of amended/revised version, second review, decision and expectations;

4. Issuance of additional guidance on SOP for post-approval monitoring as required to facilitate compliance towards ethical guidelines by the research team.

One study from India highlighted the improvements in the performance of IRB concerning the recognition of SIDCER-FERCAP that covered post accreditation and re-accreditation periods [9]. Nevertheless, no studies addressed the performance of IRBs in Myanmar that reflects the effect of the accreditation process. Therefore, this study aimed to self-evaluate the nature of ethical review process at DMR before and a year after SIDCER-FERCAP recognition and to explore the opinions of its IRB members to further strengthen the quality of ethics review. 


\section{Methodology}

This cross-sectional evaluation study used the existing IRB records and analyzed the categories of registered research proposals at the IRB (DMR), Myanmar $(n=703)$ between January 2016 and December 2019. Besides, we used three sample case reports purposely selected (title, nature of the research project, justification, study design and study population, sample size and sampling, data collection methods, ethical issues consider before approval) to exemplify the IRB decisions. We assessed the opinions of current IRB members $(n=9)$ of DMR without revealing their identity by a self-administered semi-structured questionnaire containing five items on a scale from one to 10 alongside narrative comments [10-11]. Frequency distributions and statistical averages (modal values) were computed for variables of interest. For the narrative comments, thematic analysis was done manually.

\section{Results}

Across the study period, operational research, program evaluation research, and community interventions predominated (56\%) over biomedical research. In 2019 after accreditation, the number of submitted proposals, the proportion of expedited reviews and the frequency of hearingsessions $(n=190)$ were higher than the remaining years that ranged from $158-176$. The frequency of meetings for both expedited and full board reviews has increased since 2018 compared to previous years.

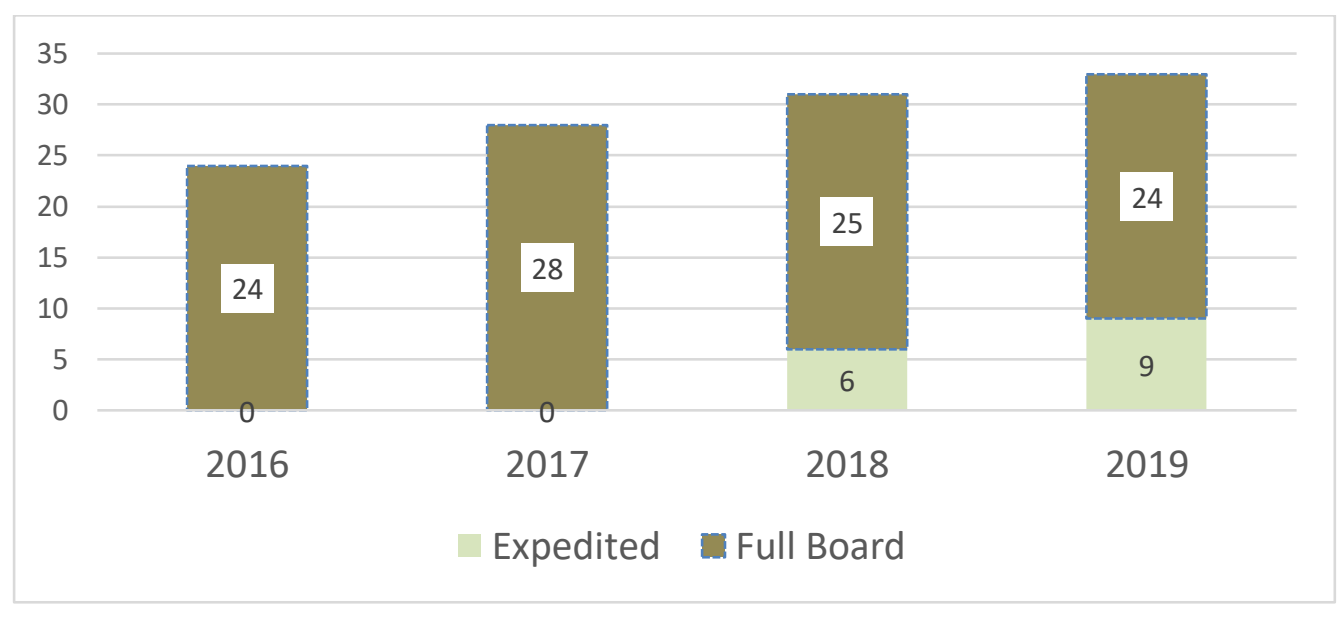

Figure 1. Distribution of review board meetings at IRB (DMR), Myanmar (2016-2019)

The turn-around time (starting from the date of submission to the date of issuance of approval certificate) varied: 6-12 weeks for the full board review and 2-4 weeks for the expedited review. The approval can get within one week for an exemption. On average, the IRB has reviewed 5-7 proposals per meeting and it usually lasted 5-6 hours for full board. There was an average of seven members in 2016 and 2017, nine in 2018 and 11 in 2019 attended the full board review meeting that surpassed the minimum quorum fulfillment of eight with the presence of at least one nonmedical, non-affiliated member. Three case examples extracted from the approval list (2019) as shown in text boxes further supported the empirical evidence of relevant decisions for major modifications and minor modifications of more than minimal risks and minimal risks applications.

\section{Sample case 1}

Title: Febrile illness evaluation in broad range of endemicity

Nature of the research project: International multi-country collaborative research

Justification: The underlying cause of fever is usually misdiagnosed or underdiagnosed due to limitations in the diagnostic facilities. Identifying the common bacterial aetiology of febrile illness will help contributing to better knowledge of epidemiology, will assist in the clinical diagnosis of 
individual febrile patients and will ultimately improve patient management, care and disease control priorities.

Objectives: To identify the causes of fever and antimicrobial susceptibility of bacterial pathogens causing fever, in low and middle income settings.

Study design and study population: Cross-sectional study and included children (10-15 years of age) Sample size and sampling: A total of 2,400 eligible children will be enrolled.

Data collection method: At the enrolment, study staff will record the basic demographic data, reported history of present illness, and duration of symptoms and will follow by nasopharyngeal swab and urine and venous blood samples according to body weight that is $100 \mathrm{ml} / \mathrm{kg}$.

\section{Ethical issues considered before approval:}

- Children as a vulnerable population should be considered to observe coercion and undue influence to parents/guardians/caretakers by the researchers during the recruitment period.

- Data collection through an invasive procedure requires an assent form for children (10-15 years).

- Technically weak research proposal may lead to unnecessary ethical considerations.

- There is a chance for more risks than benefits for the eligible children.

- The Material Transfer Agreement should cover critical issues such as ownership and access to results of materials used.

- Being a multi-country collaborative study, the research team should submit ethics approval from other international study sites.

- Detail procedures for blood samples are to be included.

- It is essential to provide timely feedback of study results to confirm diagnosis and to assist in treatment decisions.

IRB decision: Major modifications

\section{Sample case 2}

Title: Detection of Chlamydia trachomatis and Neisseria gonorrhoeae infections by a molecular-based point- of-care test using self-collected genital swab specimens obtained from patients attending the STI clinic

Nature of the research project: Local collaborative research study between DMR and STD clinic under the Department of Medical Services

Justification: Self collected swabs are easy and feasible and will be helpful in development of more consumer-friendly STD screening tests. And also self-collection process could speed up the express visits in a busy STD clinic and identify more infections compared to other methods.

Objectives: To detect Chlamydia trachomatis and Neisseria gonorrhoeae infections from self-collected genital swab specimens using a molecular-based point of care test

Study design and study population: A cross-sectional diagnostic accuracy study that will cover patients attending the STD clinic

Sample size and sampling: Altogether 300 patients will be recruited consecutively.

Ethical issues considered before approval:

- Few technical modifications

- There is a need to revise the recruitment procedure

IRB decision: Minor modifications

\section{Sample case 3}

Title: HIV testing and ART initiation in people who inject drugs and are placed on methadone in Kachin State, Myanmar

Nature of the research project: A collaborative research study between the Department of Public Health, Department of Medical Services and the National Structured Operational Research Training Initiative (SORT-IT) Program

Justification: Before 2017, national guidelines specified that HIV-infected persons should start ART if they were in WHO clinical Stage 3 or 4 or if the CD4 count $<500$ cells/ $\mu \mathrm{L}$. In 2017 , the 
guidelines were changed to align with those of the WHO, specifying that all HIV-infected persons start ART regardless of WHO clinical stage or CD4 cell count. We wanted to assess whether HIV testing and ART uptake in PWID newly enrolled for MMT and never previously tested for HIV had changed and improved in relation to the new HIV guidelines at the largest government centre. Objectives: To compare before (2016) and after (2018) adoption of 'Test and Treat' guidelines for antiretroviral therapy (ART): 1) the demographic profile of PWID, 2) HIV testing uptake and ART initiation in those diagnosed HIV-positive, and 3) time taken for events.

Study design and study population: This was a cohort study using secondary programme data.

Ethical issues addressed by IRB:

- To submit the waiver request letter for an informed consent due to the use of secondary programmatic data between 2016 and 2018.

- To revise the data transfer agreement submitted.

IRB decision: Approved with minor modification

\section{Opinion ratings}

Among others, the IRB members preferred sustained efforts in: capacity building, modification of standard operating procedures, and especially networking (modal rating of 9) (Table 1).

Table 1. Modal opinion scores of IRB members in strengthening quality ethics review $(n=9)$

\begin{tabular}{|l|l|}
\hline Opinion items & Modal score \\
\hline $\begin{array}{l}\text { Current IRB submission process could satisfy the needs of Principal } \\
\text { Investigators }\end{array}$ & 6 \\
\hline $\begin{array}{l}\text { Current IRB full board reviews could adequately manage the technical and } \\
\text { ethical requirements of the submitted research proposals }\end{array}$ & 8 \\
\hline $\begin{array}{l}\text { Current standard operating procedures of IRB could match with different types } \\
\text { of research proposals submitted }\end{array}$ & 7 \\
\hline IRB (DMR) needs to synchronize and network with other IRBs in the country & 9 \\
\hline $\begin{array}{l}\text { IRB (DMR) needs to network with other prominent IRBs in the Asia and the } \\
\text { Pacific Region }\end{array}$ & 7 \\
\hline
\end{tabular}

Table 2 generated two themes out of narrative comments: IRB submission process and issues on standard operating procedure, capacity building and networking. As for Theme (1), IRB members mainly focused the redundancies during submission process with implications for prolonged duration of turn-around time and workload of the secretariat members. Concerning Theme (2), the respondents highlighted the importance of capacity building of IRB members in support of quality ethics review in addition to regular review and revision of standard operating procedures and the necessity for funding support to IRB so as to enhance networking activities.

\section{Table 2. Narrative comments cited by IRB members}

\begin{tabular}{|l|l|}
\hline Theme (1): IRB submission process & $\begin{array}{l}\text { Theme (2): Standard operating procedures, } \\
\text { capacity building and networking }\end{array}$ \\
\hline $\begin{array}{l}\text { At the first IRB meeting, PIs usually receive } \\
\text { immediate feedback. Many of them need } \\
\text { resubmission after minor modifications and } \\
\text { should wait for the ethics approval for a while. }\end{array}$ & $\begin{array}{l}\text { To attain more benefits through IRB meetings, } \\
\text { continuous capacity building of IRB members is } \\
\text { critical. }\end{array}$ \\
\hline $\begin{array}{l}\text { The way of communication to PIs by the } \\
\text { secretariat and their attitude has an impact on } \\
\text { satisfaction of PIs. }\end{array}$ & $\begin{array}{l}\text { The SOPs need a review perhaps every year to } \\
\text { keep abreast with scientific advances, regulations } \\
\text { and statutory laws. }\end{array}$ \\
\hline $\begin{array}{l}\text { Introducing the online submission process may } \\
\text { satisfy PIs, not only convenient for them but also } \\
\text { reduce the workload of secretariat for preliminary } \\
\text { checks. }\end{array}$ & $\begin{array}{l}\text { Securing the funding support for sustainable } \\
\text { networking with prominent IRBs in the Asia- } \\
\text { Pacific region is a challenge. }\end{array}$ \\
\hline
\end{tabular}




\section{Discussion}

There was significant progress of the ethics review process of IRB at DMR, Myanmar, one year after SIDCER-FERCAP recognition [12]. However, there were challenges such as the high volume of submitted proposals, frequency of meetings and lengthy turnaround time. The workload and progress coupled with challenging decisions and opportunities for further improvement of a newly accredited IRB were also highlighted by other REC performance studies in low and middleincome countries [13-15]. Incomplete applications, poorly written research proposals and delay in submission of the amended/revised version of the proposal contributed towards lengthy turnaround time also indicated by other studies [3,9,16-17]. Quorum fulfilment was another challenge for IRB (DMR) but quorum improved dramatically in post-accreditation [9].

Following the submission of the proposals, the IRB has categorized the level of review required: full-board review, expedited review and exemption. Especially for the minimal risks proposals, the IRB has undertaken expedited reviews at the discretion of the Chairperson, by the Chair person and the Member, Secretary and a member with an appropriate expertise thus requiring less knowledge and input to reach the decision. Within the context of IRB submission process, the Principal Investigators received feedback during and after attending the IRB meeting both in form of verbal and written communication in line with the practice of other IRBs in Asia and the Pacific Region [3,14]. A vast majority required resubmission following minor modifications whilst the complex proposals particularly of international multi-centric/multisite collaborative research were most frequently subjected to major modification and substantial revisions, especially for ethical concerns. Their satisfactory revisions may lead eventually to final ethics approval after a certain period of waiting time [15-17]. The way of communication by the secretariat and their attitude might have an impact on the satisfaction of Principal Investigators (PIs) that instigated further research. Introducing the online submission system could satisfy Pls, not only make them easy but also reduce the workload of the secretariat.

Furthermore, the opinions of its IRB members indicated the needs to further strengthen the quality of ethics review. The self-assessment questionnaire informed positive viewpoints, gaps in satisfaction of researchers towards current submission process, capacity-building efforts and pragmatic solutions for quality reviews to handle as next steps $[14,18]$. Capacity building of IRB members is critical to attaining more benefits through IRB meetings. Some of the SOPs required to be specific and clear. In addition, frequent reviews and revisions of SOPs perhaps every year might pave the way to keep abreast with scientific advances, regulations and statutory laws [15]. Funding support for sustainable networking with prominent IRBs in the Asia-Pacific Region is a challenge. Owing to time constraint and feasibility as a limitation, the satisfaction of principal investigators towards the performance of IRB could not be explored to comprehend the complete picture of the quality ethics review process.

\section{Conclusion}

This study elucidates the satisfactory progress and achievements in ethical review despite a few challenges. Continuing evaluation of institutional capacity for research ethics might underscore discrepancies that would allow for improvement in quality ethics review. Future research on the development of a framework for feasible and efficient accreditation mechanism with stronger administrative support is critical.

\section{REFERENCES}

1. Heimer CA, Petty J. Bureaucratic ethics: IRBs and the legal regulation of human subjects research. Ann Rev Law Soc Sci 2010;6:601-26.

2. Jamrozik K. Research ethics paperwork: what is the plot we seem to have lost?. BMJ 2004;329(7460):286-7.

3. Kulkarni R, Saraiya U. Accreditation of ethics committees in India: Experience of an ethics committee. Indian J Med Ethics 2015;12:241-5.

4. De Vries R, DeBruin DA, Goodgame A. Ethics review of social, behavioral, and economic research: Where should we go from here?. Ethics Behav 2004;14(4):351-68.

5. Wynn LL. Ethnographers' experiences of institutional ethics oversight: Results from a quantitative 
and qualitative survey. J Policy History 2011;23(1):94-114.

6. Niemeyer DM, Calcote J, Grant E. Association for the Accreditation of Human Research Protection Programs (AAHRPP): Accreditation Overview (Updated Version). 59 MDW/ST JBSA LACKLAND United States; 2016 May 9.

7. Beagan B, McDonald M. Evidence-based practice of research ethics review. Health Law Rev 2005;13(2-3):62-8.

8. International Conference on Harmonization, Guidance on Good Clinical Practice. ICH GCP. 1996.

9. Desai AV, Hawaldar RW, Divatia JV. Role of accreditation in quality improvement of institutional review board. Perspect Clin Res 2017;8(3):145-9.

10. Sleem H, Abdelhai RA, Al-Abdallat I, Al-Naif M, Gabr HM, Kehil ET, Sadiq BB, Yousri R, Elsayed D, Sulaiman S, Silverman H. Development of an accessible self-assessment tool for research ethics committees in developing countries. J Empirical Res Hum Res Ethics 2010;5(3):8598.

11. Silverman H, Sleem H, Moodley K, Kumar N, Naidoo S, Subramanian T, Jaafar R, Moni M. Results of a self-assessment tool to assess the operational characteristics of research ethics committees in low-and middle-income countries. J Med Ethics 2015;41(4):332-7.

12. SIDCER Recognition Programme. Available at: http://www.fercap-sidcer.org/recog.php (cited 21 November 2018)

13. Kadam R, Karandikar S. Ethics committees in India: Facing the challenges!. Perspect Clin Res 2012;3(2):50.

14. Edwards HA, Hifnawy T, Silverman H. Enhancing Research Ethics Review Systems in Egypt: The Focus of an International Training Program Informed by an Ecological Developmental Approach to Enhancing Research Ethics Capacity. Developing World Bioethics 2015;15(3):199-207.

15. Sleem H, El-Kamary SS, Silverman HJ. Identifying structures, processes, resources and needs of research ethics committees in Egypt. BMC Medical Ethics 2010;11(1):12.

16. Upshur RE. Ask not what your REB can do for you; ask what you can do for your REB. Can Fam Physician 2011;57(10):1113-4.

17. Byerly WG. Working with the institutional review board. Am J Health-System Pharm 2009;66(2):176-84.

18. Matar A, Silverman H. Perspectives of Egyptian research ethics committees regarding their effective functioning. J Empirical Res Hum Res Ethics 2013;8(1):32-44.

19. Page SA, Nyeboer J. Improving the process of research ethics review. Res Integrity Peer Rev 2017;2(1):14-9.

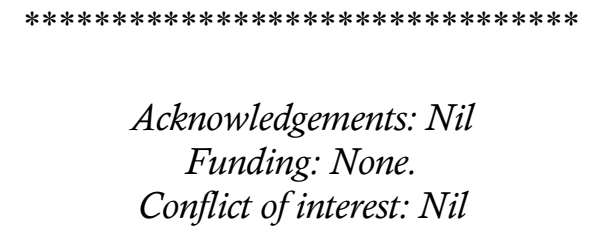

